\title{
Giovanni Pascoli, Bonnefoy traduce Pascoli
}

\section{Fabio Scotto}

\section{(2) OpenEdition}

\section{Journals}

\section{Edizione digitale}

URL: http://journals.openedition.org/studifrancesi/2289

DOI: 10.4000/studifrancesi.2289

ISSN: 2421-5856

\section{Editore}

Rosenberg \& Sellier

\section{Edizione cartacea}

Data di pubblicazione: 1 aprile 2014

Paginazione: 188

ISSN: 0039-2944

\section{Notizia bibliografica digitale}

Fabio Scotto, « Giovanni Pascoli, Bonnefoy traduce Pascoli », Studi Francesi [Online], 172 (LVIII | I) | 2014, online dal 01 avril 2014, consultato il 18 septembre 2020. URL : http://journals.openedition.org/ studifrancesi/2289; DOI : https://doi.org/10.4000/studifrancesi.2289

\section{Questo documento è stato generato automaticamente il 18 settembre 2020.}

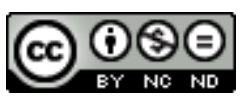

Studi Francesi è distribuita con Licenza Creative Commons Attribuzione - Non commerciale - Non opere derivate 4.0 Internazionale. 


\title{
Giovanni Pascoli, Bonnefoy traduce Pascoli
}

\author{
Fabio Scotto
}

\section{NOTIZIA}

GIovanNi PASColi, Bonnefoy traduce Pascoli, a cura di Chiara elefante, Faenza, Mobydick, 2012 («L'Immaginario», 29), pp. 70, con allegato CD con diciannove poesie di Giovanni Pascoli interpretate da Yves Bonnefoy, Angela Baviera e Gabriele Marchesini.

1 Il grande poeta francese Yves Bonnefoy aggiunge con questo libro un'altra preziosa tessera al suo catalogo italiano, dove già figurano Leopardi e Petrarca. Nel suo saggio introduttivo «La poesia di Giovanni Pascoli affidata alla voce poetica di Yves Bonnefoy» (pp. 7-17), Chiara ELEFANTE ripercorre l'avventura della ricezione della poesia di Pascoli in Francia, caratterizzata da vicissitudini e malintesi che, dal tentativo di Marinetti di contrapporlo a D'Annunzio alle versioni poetiche che avevano contribuito a tramandarne per lo più l'immagine del poeta rurale della famiglia e dei buoni sentimenti, non avevano giovato a una più oggettiva e completa conoscenza della sua opera oltralpe.

2 La curatrice passa poi a indicare i criteri che hanno ispirato le scelte testuali fatte da Bonnefoy, che escludendo i testi di taglio più storico-politico, hanno privilegiato quelli nei quali i fenomeni naturali o le apparizioni di oggetti affidate a uno stile paratattico e nominale sono trattati in modo quasi cinematografico e alludono all'immediatezza del qui ed ora dell'esistenza e delle sue presenze nella quotidianità. E, sul piano traduttivo, il poeta francese, pur evitando i testi nei quali domina l'onomatopea, a suo avviso non riproducibile in francese se non a rischio di esiti ridicoli, focalizza il suo interesse «sulla musicalità, sulle sonorità e il ritmo della poesia pascoliana» (p. 9), come ben dimostrano le analisi di alcuni passi traduttivi condotte nella parte terminale del saggio, dalle quali emerge la poetica del tradurre di Bonnefoy, incentrata sull'esigenza di tradurre in versi liberi attuali e in modo ricreativo e personale, così da stabilire un rapporto di 
reciprocità maieutica, per così dire, fra la lirica del tradotto e quella del traduttore. Elefante ben mostra qui, attraverso evidenziazioni delle serialità foniche messe in atto dalla traduzione, come il traduttore, sensibile all'oralità della scrittura, abbia «cercato di spostare dal piano delle scelte lessicali al piano della sintassi e del ritmo la coinvolgente musicalità pascoliana» (p. 11).

3 Ne risulta un Pascoli francese particolarmente singolare e coinvolgente, come attesta anche all'ascolto il pregevole $\mathrm{CD}$ allegato al volume, tradotto secondo principi che sono quelli ora riformulati nel recente libro di saggi sulla traduzione di Yves Bonnefoy dal titolo L'Autre langue à portée de voix (Paris, Seuil, 2013 «La librairie du XxI siècle», pp. 333), dove si può leggere, in quarta di copertina, questa icastica affermazione, che in se stessa condensa larga parte della problematica traduttiva e della riflessione che su essa da secoli si compie: «La neige tombe-t-elle semblablement dans toutes les langues?». 